\title{
Sou linda, sou Shirley, me inventei
}

Elisabeth da Rocha Miranda

\begin{abstract}
Resumo
$\mathrm{O}$ artigo discute que não há identidade sexual dada de saída para o sujeito, pois nos constituímos sempre por um parecer ter ou parecer ser o falo. Pertencer a um sexo depende do preço que terá adquirido no desenrolar da vida a pequena diferença, logo depende da maneira como cada um se situa diante do significante falo. Não existe o significante que represente a mulher, nem o homem, há um só operador que permite no inconsciente dar conta da diferença sexual, e esse operador é o falo.
\end{abstract}

\section{Palavras-chave:}

Posição sexuada; Posição subjetiva; Falo; Semblante.

\section{I'm beautiful, I'm Shirley, I've invented myself}

\begin{abstract}
The article discusses that there is no sexual identity given out to the subject, because we are always constituted by an opinion to have or appear to be the phallus. Belonging to a sex depends on the price that the small difference will have acquired in the course of life, so it depends on the way each one stands before the significant phallus. There is no signifier that represents the woman or the man, there is only one operator that allows the unconscious to account for the sexual difference, and this operator is the phallus.
\end{abstract}

\section{Keywords:}

Sexual position; Subjective position; Phallus; Semblant.

\section{Soy linda, soy Shirley, me he inventado}

\section{Resumen}

El artículo discute que no hay identidad sexual dada de salida para el sujeto, pues nos constituimos siempre por un parecer tener o parecer ser el falo. Pertenecer a un sexo depende del precio que habrá cobrado a lo largo de la vida la pequeña 
diferencia, luego depende de la manera como cada uno se sitúa ante el significante falo. No existe el significante que represente a la mujer y al hombre, hay un solo operador que permite en el inconsciente dar cuenta de la diferencia sexual y ese operador es el falo.

\section{Palabras clave:}

Posición sexuada; Posición subjetiva; Falo; Semblante.

\section{Je suis belle, je suis Shirley, je me suis inventée}

\section{Résumé}

Cet article propose qu'il n'y a pas d'identité sexuelle donnée d'emblée au sujet, car nous sommes toujours constitués de faire semblant d'avoir ou de faire semblant d'être le phallus. Appartenir à un sexe dépend du prix que la petite différence aura acquis au cours de la vie, et cela relève donc de la façon dont chacun se situe face au significant phallus. Il n'y a pas de signifiant qui représente la femme ou l'homme, il n'y a qu'un seul opérateur qui permette, dans l'inconscient, de rendre compte de la différence sexuelle, et cet opérateur est le phallus.

\section{Mots-clés:}

Position sexuelle; Position subjective; Phallus; Semblant.

Desde 1905, com o texto freudiano Os três ensaios sobre a teoria sexual (1905/2011) e posteriormente com Lacan e o conceito de real, sabemos da desnaturalização radical da sexualidade humana. Há uma impossibilidade de naturalização da sexualidade e, consequentemente, da heterossexualidade pelo fato da inserção da linguagem no vivente. É a linguagem que insere o humano na partilha dos sexos como homem ou mulher, e não a anatomia, portanto é o discurso que nos dá a realidade sexual. Meu corpo que também sou, eu o tenho esculpido pelo significante vindo do Outro e pelo real como marca de gozo.

Pois, logo ao nascer, somos distinguidos pelo Outro da linguagem como homens e mulheres a partir da pequena diferença (Lacan, 1971-1972/2012, p. 16). É uma distinção vinda do Outro e que foge à lógica, constituindo um paradoxo, uma vez que, para nos reconhecermos como seres falantes na partilha dos sexos, é preciso justamente rejeitarmos tal distinção e nos submetermos à necessária castração como operação simbólica cujo objeto é imaginário. É necessária a falta para entrarmos na dança dos desejos edipianos. Não há para o ser de fala uma identidade a priori que o situe na partilha dos sexos, e muito menos uma identidade adequada ao corpo; o que há são as identificações decorrentes da vivência 
edípica, em que as possibilidades são múltiplas. A identidade sexual virá para cada um como a cristalização dessas identificações, conforme Lacan em 6 de novembro de 1976 (Lacan, 1976-1977, inédito).

Pertencer a um sexo depende do valor que terá adquirido no desenrolar da vida a pequena diferença, logo depende da maneira como cada um se situa diante do significante falo. Não existe o significante que represente a mulher, nem o homem, há um só operador que permite no inconsciente dar conta da diferença sexual, e esse operador é o falo.

A identificação com um sexo e a diferença entre os sexos estariam centradas no significante falo, significante da falta. O sujeito responde à falta no Outro simbólico com o sintoma, que comporta um gozo residual, graças ao qual podemos sustentar a não relação sexual. Se não há identidade sexual dada de saída para o sujeito, resta-nos o semblante: constituímo-nos sempre por um parecer ter ou parecer ser o falo.

Em 1972, Lacan, a respeito das normas em matéria sexual, diz que, se não há relação sexual, a heterossexualidade como prática social é apenas um semblante. Os sexos são dois, a diferença é real, mas homem e mulher são apenas significantes de valores sexuais, e a heterossexualidade é, nesse sentido, um semblante consolidado pela função do casamento, que parece instituir uma relação lá onde ela não existe (Lacan, 1971-1972/2012).

O conceito de semblante se encontra na via que vai do simbólico ao real. A oposição entre semblante e real é a essência mesma da psicanálise, na medida em que o real faz vacilar os semblantes civilizatórios, o que constitui um retorno ao real do sexo; logo, o semblante resulta do esforço do simbólico para apreender o real. O sujeito percorrendo o caminho, pelo desfile de significantes que vai do simbólico ao real, encontra o semblante, a aparência de ser, ou seja, o lugar em que, no triângulo, Lacan situa o objeto $a$, como vemos no grafo (Figura 1) (Lacan, 1972-1973/2008, p. 128).

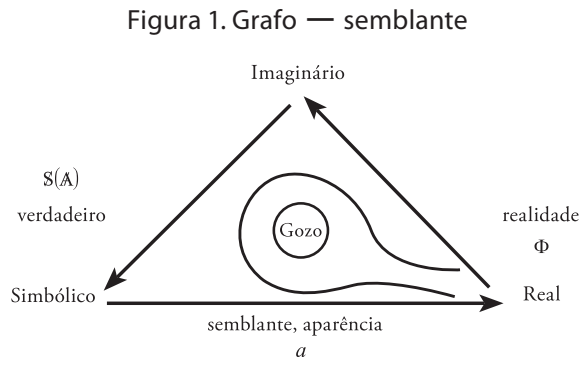

Fonte: Lacan, 1972-1973/2008, p. 128.

Nessa via do simbólico ao real, os que se situam como homens fazem semblante de ter o falo, e os que se situam como mulheres fazem semblante de, por não tê-lo, ser o falo, mas ela não o tem em relação àquele que tem; logo, a alteridade feminina seria aqui definida em relação ao falo, ou seja, como determinada pela lógica falocêntrica. 
Se Freud resolve a questão da diferença sexual em termos de identificação a partir da lógica falocêntrica, Lacan avança e postula a lógica do não-todo fálico. Haveria, então, o fálico e o não-todo fálico.

Nos anos 1972-1973, Lacan emprega o termo sexuação, colhido da biologia, para acentuar a dimensão de processo da função sexual, apresentando o que chamou de fórmulas da sexuação.

Essas fórmulas especificam as relações do sujeito com o gozo; estão do lado masculino (lado $\mathrm{H}$ ) daqueles que experimentam um gozo todo fálico e do lado feminino (lado F) daqueles que experimentam um gozo não-todo fálico. Então, a posição masculina é assumida por aqueles que se dirigem ao objeto $a$ pulsional, objeto de desejo e gozo, objeto da fantasia. Desse lado, situam-se todos os sujeitos que esperam alcançar o objeto fantasmático e que, assim, poderiam eliminar a falha que impede toda possibilidade de realização do gozo total. Do lado masculino, temos a coexistência da posição sexuada com a posição subjetiva.

Do lado feminino, Lacan parte da mulher barrada (La femme barrada). Aqui, a posição sexuada é radicalmente separada da posição subjetiva. A mulher pode se colocar na posição de objeto do outro como a (objeto de desejo e/ou gozo), e como A mulher (La femme barrada) se dirige ou ao falo, ou ao significante da falta no Outro. Dirigindo-se ao falo, vai buscar o significante do desejo no outro. Dirigindo-se ao $\mathrm{S}(\mathbb{A})$, vai ao lugar da falta de um significante no Outro, lugar de vazio, e aí o sujeito experimenta uma relação com o nada, com a falta de significantes que pode levar ao êxtase.

Essas posições circulam, não estamos sempre em uma ou em outra, estamos ora na posição masculina, ora na posição feminina. Vejamos um fragmento clínico.

\section{0 caso Shirley}

Shirley chega ao consultório acompanhada pelo marido, queixando-se das imposições dele, que, por sua vez, diz já não aguentá-la mais com tantas exigências e agora, além disso, está preocupado porque ela escuta vozes. Ela, por sua vez, diz que eles têm brigado muito, porque "Daniel só pensa em família... até a sogra ele quer sempre junto, e eu não tenho saco para minha mãe. Quer filho, e eu, não. Iria me atrapalhar muito profissionalmente, eu viajo muito por conta de ser miss desde 2013. Ele é um chato, mas eu gosto dele. Estamos juntos há 12 anos”.

Shirley tem duas irmãs mais velhas.

"Somos três. Minha mãe apanhou muito do meu pai, homem grande, bonito e muito rude. Ganhava dinheiro com falsificações do INSS, essa mamata de aposentadoria. Bebia e gastava tudo com mulheres, depois voltava para casa duro e batia na minha mãe e em minhas irmãs, era um horror. Em mim, ele nunca batia, nós não nos olhávamos, eu tinha muito medo e muita raiva. Sabe, às vezes penso que nem para apanhar eu servia. Lembro de uma coisa muito estranha na adolescência. 
É que meu pai vivia dizendo: 'Essa saliência toda vai acabar quando você fizer 18 anos! Aí, sim, você vai conhecer o peso de minha mão!' Pensava o porquê que a mim ele só bateria quando eu fizesse 18 anos se em minhas irmãs ele metia a mão desde criança. Nunca entendi isso, mas ele morreu de cirrose quando eu tinha 14 anos e não conheci o peso da mão de meu pai. Eu achava que ele só gostava das três [mãe e duas irmãs], e não de mim. Acho que é por isso que provoco o Daniel, para ele me dar uns tapas, mas acaba que eu bato mais nele do que ele em mim. No fundo, quando tudo passa, percebo que poderia ter acontecido uma tragédia e me assusto com a minha própria violência. Será que sou como meu pai? Que horror!!”

Depois de se assegurar de que Daniel jamais saberia do que ela fala ali, afinal ele invade tudo, ela confessa: "Certo ou errado, eu faço coisas, mas que são para conseguir algumas atitudes com o Dani, senão ele só faz o que a mãe dele quer e o que minha mãe também, ele escuta demais as duas. Dizer que falo com os espíritos me faz poderosa, ele acredita em tudo o que eu digo, e foi assim que consegui com que ele comprasse o nosso apartamento mesmo contra a opinião de minha mãe e da dele. Essas velhas querem que a gente volte para o interior, e não volto por nada. Mas uma coisa é de verdade: eu gosto da natureza, faço meditação na mata, na praia, mas se relaxo muito sinto uma espécie de transe que me dá um enorme bem-estar."

Depois de quatro sessões, Shirley entra e diz: "Hoje, vou trabalhar, por isso estou de Junior. Desculpe, é que eu sou maquiador particular de uma estrela global e também trabalho na TV Globo, e lá tenho que ser Junior, veado, entende?" Pergunto qual o seu primeiro nome. "Bem, Jorge Augusto era o meu pai. Junior não é nome, e aí eu inventei a Shirley. Ganho algum dinheiro com desfiles e shows. Shirley é uma montagem, uma brincadeira, e os homens adoram quando depois de tudo aparece o... quer dizer, o órgão, o Jorge Augusto, sabe?”

A anatomia decide apenas o estado civil, mas não controla nem a pulsão nem o desejo; logo, o que importa na diferença entre os sexos são as consequências psíquicas dessa diferença.

Na partilha dos sexos, temos, de um lado, a questão das identificações - "as características sexuais e a atitude sexual do sujeito" - e, de outro, a "escolha de objeto", ambas resultantes da experiência edípica. As identificações vacilam no encontro com o real e com o objeto, que, como se sabe, é o que há de mais variável quando se trata de satisfazer a pulsão, que é sempre é sexual.

Junior é miss Brasil e por isso passeia, viaja e faz compras como Shirley, moça bonita, discretamente vestida e até elegante. Não tem silicone, nem quer ser operado; "não sou uma deformidade, sou homem, gosto de homem, gosto do meu órgão, não quero seios, mas olha só; sou uma linda mulher quando estou de Shirley! Tudo é uma questão de se parecer com o que se quer ser".

Junior, Jorge Augusto ou Shirley nos dá uma aula sobre o semblante. Nas fórmulas, vemos como esse sujeito transita de um lado para o outro, da posição masculina de 
sujeito desejante para a posição de objeto. Na posição feminina, busca o falo em forma de joias, perucas, desfiles, tapete vermelho, coroa de rainha, o homem etc., e é também capaz de cair no abismo de $\mathrm{S}(\mathbb{A})$ quando, por exemplo, entra em seus transes.

A partir da marca de gozo, que toca a letra, traço perdido no encontro com o Outro, Jorge Augusto inventa Shirley, semblante de ser mulher resultado do esforço do simbólico para apreender o real do sexo. Shirley encarna a alteridade, a outra ela, a não-toda para ela mesma e para o parceiro, que, por sua vez, não sabe o que fazer com isso. Shirley, portanto, presentifica o ser sexuado como efeito do encontro com o significante, e não com a anatomia.

\section{Referências bibliográficas}

Freud, S. (1905/2011). Três ensaios sobre a teoria da sexualidade. (José Luis Etcheverry, Trad.). In J. Strachey (Ed.). Obras completas (Vol. 7, 2a. ed., pp. 109-224). Buenos Aires: Amorrortu.

Lacan, J. (1971-1972/2012). O seminário, livro 19: ...ou pior. (Vera Ribeiro, Trad.). Rio de Janeiro: Jorge Zahar.

Lacan, J. (1972-1973/2008). O seminário, livro 20: mais, ainda. (M. D. Magno, Trad.). Rio de Janeiro: Jorge Zahar.

Lacan, J. (1976-1977). O seminário, livro 24: l’insu que sait de l'une-béveu s'áile à mourre. Inédito.

Recebido: 15/10/2017

Aprovado: 26/01/2018 